\title{
Causes of Delay in the Construction Projects of Subway Tunnel
}

\author{
Dingbang Zhang $\mathbb{D}^{1}{ }^{1}$ Hang Zhang, ${ }^{2}$ and Tao Cheng ${ }^{1}$ \\ ${ }^{1}$ School of Civil Engineering, Hubei Polytechnic University, Huangshi 435003, China \\ ${ }^{2}$ South Engineering Co., Ltd., Chinese Railway Bridge Engineering Bureau Group Company, Guangzhou 510000, China \\ Correspondence should be addressed to Dingbang Zhang; ericzdb@126.com
}

Received 15 July 2020; Revised 10 August 2020; Accepted 30 October 2020; Published 20 November 2020

Academic Editor: Sanjay Nimbalkar

Copyright (c) 2020 Dingbang Zhang et al. This is an open access article distributed under the Creative Commons Attribution License, which permits unrestricted use, distribution, and reproduction in any medium, provided the original work is properly cited.

\begin{abstract}
The constructions of urban infrastructure are an important sector that provides remarkable ingredients for the economic development of modern cities. However, a large number of transportation infrastructure construction projects are delayed; therefore, those projects always exceed their original time and cost estimates. So construction delay has been considered as a recurring problem in the construction projects of urban infrastructure, and it adversely affects the time, cost, safety, and quality of construction. This paper is committed to investigating the time performance of subway tunnel constructions in China to identify the causes of delay based on the questionnaire surveys of 87 tunnel consultants and 91 contractors, and a total of 49 delay causes of tunnel construction are identified one by one in this study. It can be concluded from this study that the six most severe delay causes are national policy for subway tunnel construction, complicated geological conditions, payment delays by owners, award projects to the lowest bid price, shortage of advanced large equipment, and low productivity of laborers. There is a relatively reliable agreement between the tunnel consultants and contractors of $76.3 \%$ on the ranking of different delay causes.
\end{abstract}

\section{Introduction}

The constructions of urban infrastructure are one of the best tools through which a country or a region can achieve its economic goals of urban development [1], they have a remarkable effect on the economy of all countries and regions of the world [2]. Because the tunnel constructions are long processes and many parties are involved in the processes such as clients, designers, consultants, contractors, and subcontractors, tunnel constructions are becoming more and more complex [3]. Delay in the construction projects may produce adversarial and mistrust relationships, litigation and arbitration problems, and trepidation feelings among clients, designers, consultants, contractors, and subcontractors [4]. Whether the construction projects are successful or not depend on prime measures including time, cost, safety, and quality, any construction project may not be taken as a success unless it meets these specified requirements, and it is common to see a construction project failing to achieve its original time goal [5]. The delays in infrastructure construction projects became a universal phenomenon around the world.

According to the government work report, it can be known that $13 \%$ of gross domestic product (GDP) was contributed by construction projects in China, while only $6-9 \%$ of the GDP was contributed by construction projects in many countries and regions. The relatively high proportion of GDP in China shows that the sector of construction projects intensively affects various social, educational, and other sectors. With the substantial success achieved by the construction projects in terms of economic growth, labor output, and employment, these construction projects are partially meeting the local needs of Chinese society. However, more and more construction projects suffer from some problems which may prevent them to achieve their original time, cost, safety, and quality goals in the economy [6]. According to Al-Najjar's work [7], the main problems are as follows: 
(i) The number of construction projects in comparison with a large number of local workers

(ii) Continued increase in material and labor prices

(iii) Dependency on government investments to implement construction projects of infrastructure

(iv) Complicated geological conditions in different areas

In China, the general investigations have indicated that construction project delay is a common phenomenon, but there are no former researches which have carefully investigated the causes of project delay in subway tunnel construction. This paper aims to investigate the most severe delay causes of subway tunnel projects in China. Identifying causes is always the basic work when catching a problem, and then corrections can be done [8], so it is hoped that the studies of this paper may guide further works to improve the performance of the projects especially in the subway tunnel construction.

\section{Literature Review}

Construction projects are often faced with delays, and projects finish later than the dates fixed in construction contracts. Analysis of construction delay is usually based on the identification of delay causes since it is a determination of causation, quantification of delay, and assessment of responsibility in its simplest form $[9,10]$. With the complex and multiparty nature of modern construction projects, it is a daunting task to identify the delay causes [11, 12].

Al-Momani studied the causes of delay which were related to the owner, designer, contractors, and consultants in more than 100 public projects in Jordan [13]. Odeh and Battaineh concluded that the top 6 severe causes of construction delay in Jordan were owner's interference, slow decision making, payment delays by owners, improper plans, inadequate experience, and low labor productivity [14]. Assaf and Al-Hejji identified the causes of delay in Saudi Arabia, and it concluded that the most common cause of delay was that the owners change orders [15]. Ahn and Minchin made a comparison between contract types (unit cost, lump sum, and others) which shows the average increase in construction time using innovative contracts was $14.8 \%$, whereas the increase for low bid contract was $30.0 \%$, the average time overruns of bonus contracts was only $1.8 \%$ which was shortest among the studied innovative contracting methods [16]. Enshassi and Abu Mosa found that the most important delay cause was employing an unqualified designer to conduct the design and defective design may cause quality accidents [17]. Yang et al. identified the delay causes in various stages of BOT projects by the opinions of BOT participants, and the study results revealed that the "improper contract planning," "debt problem," and "uncertainty on political issues" were the most significant delay causes [18]. Mahamid et al. studied the delays in road construction projects in Palestine which concluded that the terrible political situation, segmentation, and limited movement between areas are the most severe delay causes [19]. Santoso and Soeng analyzed the delay factors in road construction projects in Cambodia, it concluded that rain and flood were the first two factors, and there was no significant difference between contractors and consultants in assessing the delay factors [20]. Alfakhri et al. proposed a conceptual model of delay factors and used the Statistical Package for Social Sciences (SPSS) software to analyze the level of impact of identified delay categories on the completion of the road construction projects, it concluded that the contractor had the most significant impact on the delay in road projects, and the conversion and transfer of utility services by the competent authorities were the five most significant factor [21]. Bilgin et al. proposed a delay analysis ontology to facilitate the development of databases, information sharing as well as retrieval for delay analysis within construction projects $[22,23]$.

Out of these studies, it can be concluded that the studies about the time delays in subway tunnel construction in developing countries are seldom to see.

\section{Study Objectives}

The main study goals of this paper are as follows:

(i) To identify the causes of delays in subway tunnel construction projects in China

(ii) To identify and rank the severe delay causes according to the viewpoints of a large number of contractors and consultants

(iii) To test the agreements between a large number of contractors and consultants on the rank of the severe delay causes

\section{Research Design}

4.1. Research Method. Based on the questionnaire surveys of project participants, the necessary information about project delays is obtained in an effective way. More than 40 delay causes of project delays are generated from related studies together with input, output, and revisions by some construction parties, the list of delay causes are shown in Table 1. The questionnaire surveys are also adopted to estimate the severity of all the delay causes.

The studied project participants mainly involve contractors and consultants, the contractors are holding the valid registrations in tunnel specialization within China from the Chinese Contractors Association. The studied project participants do not involve owners because the subway tunnel construction projects are public infrastructure projects which are always funded by the local governments, it means that there is only one owner for each project and so the view of the owner is not collected through a questionnaire survey. The studied contractors and consultants are selected by random sampling from an available list. The detailed communication information of studied contractors and consultants are obtained from the database of the Chinese Contractors society.

Data are obtained from the questionnaire surveys of contractors and consultants and studied by adopting a severity index. The agreement between the two kinds of parties on the severity rank of the delay causes is also tested. Some 
TABLE 1: List of delay causes and related classification.

Main classification

(1) Owner

(2) Designer

(3) Contractor

(4) Consultant

(5) Labor

(6) Environment

(7) Equipment

(8) Material

(9) External factors

suggestions making for reducing the project delays in subway tunnel construction are emphasized in the study results.

4.2. Questionnaire Survey. The questionnaire surveys are divided into two parts. Part one is connected with the integrated information for both the construction companies and
Causes under each classification

Late issuing the approval documents by the owner

Change orders by the owner during construction period

Poor communication between the owner and other construction parties

Postponement of the project by the owner

Progressing payments delay by the owner

Delays in decision making by the owner

Delay in providing construction materials

Poor financial status of the owner

Late land handover to the contractor by the owner Undefined scope of working

Inappropriate design

Late design works

Mistake in design

Improper construction method

Poor site supervision by the contractor

Rework because of errors during construction

Ineffective scheduling of the project by the contractor

Conflict between the contractor and other parties

Difficulties in financing the project by the contractor

Poor resource management

Poor communication by the contractor with other construction parties

Incapable and Insufficient inspectors

Poor communication between the consultant and other construction parties

Inflexibility of the consultant

Delay of inspection by the consultant

Insufficient laborers

Personal conflicts among laborers

Low skill level of equipment-operator

Low productivity of laborers

Conflict between laborers and management team

Poor terrain condition and wall rock quality

Natural disaster

Weather condition

Poor effect on the drainage system

Complicated geological conditions

Lack of equipment efficiency

Shortage of advanced large equipment

Serious damage to the equipment

Changes in material types and specifications during construction

Shortage in construction material

Material loss in the process of transportation

Increasing prices of raw materials

Award the project to lowest bid price

Changing of bankers' policy for loans

Limited construction area

Inconvenient site access

National policy for subway tunnel construction

Lag in technology

Disturbance to public activities responders. The selected contractors and consultants are both requested to respond to the questions about their tunnel construction experience, and they are also further requested to respond to the questions related to their opinions about the causes of project delays according to their tunnel construction experience. Part two contains the detailed list of identified delay causes in subway tunnel construction projects, and the delay causes are in nine kinds of classification in terms of delay 
sources from the owner, designer, contractor, consultant, labor, environment, equipment, material, and external factor. Two questions in the questionnaires are as follows:

(1) In your opinion, what is the occurring probability of each delay causes? The occurring probability ranges from 0.1 to 1

(2) What is the severity degree of each delay causes on subway tunnel construction? The severity is classified into six degrees, which is on a zero to five-point chosen range, as no influence, very low, low, medium, high, and very high

\section{Data Analysis}

5.1. Severity Index. The severity index is used to rank the suggested delay causes in subway tunnel construction projects. Based on the impact degrees which are chosen by the questionnaire participants, the formula of severity index can be given as follows:

$$
\text { Severity } \operatorname{index}(\%)=100 \times \sum \alpha \times \beta \times \frac{(n / N)}{5},
$$

where $\alpha$ is the occurring probability of each delay causes; $\beta$ is the classified degree which ranges between one for no influence and six for very high; $n$ is the number of the participants who respond to the questionnaires; and $N$ is the number of all the participants who receive the questionnaires. Therefore, once the classified degree of a cause is one for no influence in all the responses, then the severity index of this cause equals zero, it means that this cause is not a significant one and at the last of rank. Conversely, once the classified degrees of a cause are six for very high influence in all the responses, then the severity index of this cause equals $80-100$, it means that this cause is a significant one and at the top of the rank. The correspondence between the possible ranges and impact degrees for the severity index is shown in Table 2. The severity index for each cause can be calculated by formula (1) from the opinions of all the respondents. The average severity index of each classification can be calculated according to the severity index of causes under each classification, the calculation formula is given as follows:

$$
\text { Classification severity index }(\%)=100 \times \sum_{i=1}^{n} \frac{X_{i}}{m},
$$

where $X_{i}$ is the severity index of cause $i$ under a classification; and $m$ is the number of causes under this classification.

5.2. Rank Correlation. In order to test how well the responsive consultants and contractors agree on the ranking according to the severity index of delay causes, a rank correlation coefficient $(0 \leq r \leq 1)$ is adopted to evaluate the rank difference between consultants and contractors. The calculating formula of the rank correlation coefficient can be given as follows:
TABle 2: Possible ranges and impact degrees for the severity index.

\begin{tabular}{lc}
\hline Range & Impact degrees \\
\hline$R=0$ & No influence \\
$0 \leq R<20$ & Very low \\
$20 \leq R<40$ & Low \\
$40 \leq R<60$ & Medium \\
$60 \leq R<80$ & High \\
$80 \leq R \leq 100$ & Very high \\
\hline
\end{tabular}

$$
r=1-\left[6 \times \sum \frac{d^{2}}{k^{3}-k}\right]
$$

where $d$ is the difference of ranks between consultants and contractors for each delay cause; $k$ is the number of pairs of different ranks. Once the rank correlation coefficient equals one, it means the two ranks are completely reverse. Once the rank correlation coefficient equals zero, it means the two ranks are the same.

\section{Study Results}

A total of 100 tunnel consultants and 100 tunnel contractors have received the questionnaires, a total of 87 tunnel consultants and 91 contractors have responded to the question about their opinions on the severity and ranking of 49 delay causes, the response rate by consultants and contractors are both higher than $85 \%$. All the respondents have more than five years of experience in tunnel construction.

6.1. Analysis of Delay Rate in Subway Tunnel Construction Projects. The responses of consultants and contractors about the delay rate in subway tunnel construction projects during the last 5 years are shown in Figures 1 and 2. Figure 1 shows that $68.8 \%$ of the responding consultants pointed out that the average durations of their participated tunnel projects are $20 \%-30 \%$ longer than the planned project durations, while $15.6 \%$ of them thought that the average durations are $30 \%-40 \%$ longer, while $9.4 \%$ of them thought that the average durations are $40 \%-50 \%$ longer, and only $6.3 \%$ of them thought that the average durations are 50\%-100\% longer than the planned project duration. Figure 2 shows that $8.6 \%$ of the responding contractors pointed out that the average duration of their participated tunnel projects are $0 \%-10 \%$ longer than the planned project durations, while $68.6 \%$ of them thought that the average durations are $20 \%-30 \%$ longer, while $17.1 \%$ of them thought that the average durations are $30 \%-40 \%$ longer, and only $5.7 \%$ of them thought that the average durations are $40 \%-50 \%$ longer than the planned project duration.

6.2. Ranking of Delay Causes. The causes under each source from different classifications are ranked according to the severity index. According to the view of both consultants and contractors, the severity index is calculated by formula (1). 


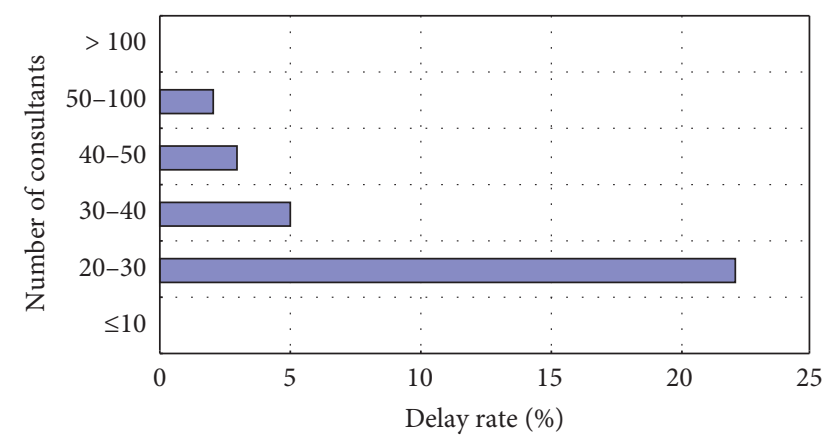

FIGURE 1: Delay rate in tunnel construction projects according to the responding consultants.

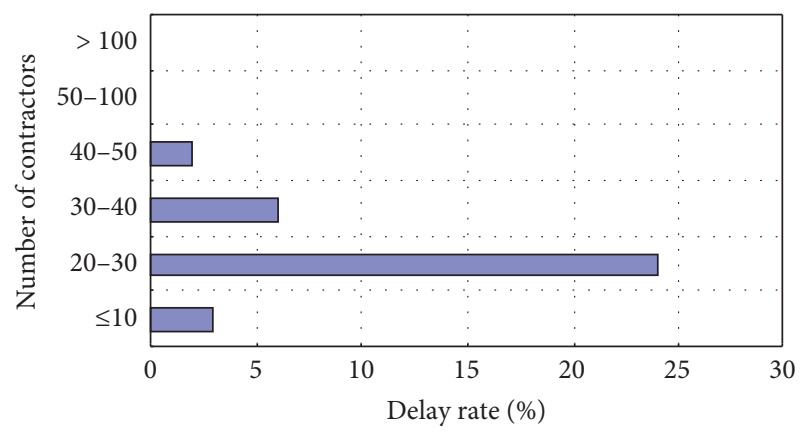

Figure 2: Delay rate in tunnel construction projects according to the responding contractors.

\subsubsection{Cause Ranking from Different Classifications}

(1) Causes from the Owner. The severity index and ranking of each delay cause from the owner in the view of consultants and contractors are shown in Table 3. It can be concluded from Table 3 that the severest cause from the owner is the progress payment delay by the owner. It also can be concluded from Table 3 that the cause rankings in the view of consultants are almost similar with the view of contractors, but there is a significant difference in the ranking of "poor communication between the owner and other construction parties" which respectively rank 4 and 7 in the view of consultants and contractors. There is a span in causes ranking in the combined view of consultants and contractors which ranges from $50.11 \%$ to $72.19 \%$ which means that each cause from the owner has a medium or high effect on the delay of subway tunnel construction projects.

(2) Causes from the Designer. The severity index and ranking of the 3 delay causes from the designer in the view of consultants and contractors are shown in Table 4. It can be concluded from Table 4 that the severest cause from the designer is late design works. It also can be concluded from Table 4 that the cause rankings in the view of consultants are almost similar with the view of contractors, but there is a small span in causes ranking in the combined view of consultants and contractors which ranges from $41.93 \%$ to $55.39 \%$ which means that the severities of the causes from the designer are still in the medium level.
(3) Causes from the Contractor. The severity index and ranking of the 8 delay causes from the contractor in the view of consultants and contractors are shown in Table 5. It can be concluded from Table 5 that the severest cause from the contractor is the ineffective scheduling of projects by the contractor. It also can be concluded from Table 5 that there are little differences between the rankings in the view of consultants and the view of contractors, one of the differences is the cause ranking of "ineffective scheduling of project by the contractor" respectively rank 1 and 2 in the view of consultants and contractors, e.g., there is a span in causes ranking in the combined view of consultants and contractors which ranges from $43.82 \%$ to $63.95 \%$ which means that the severities of the causes from the contractor are in the levels between medium and high.

(4) Causes from the Consultant. The severity index and ranking of the 4 delay causes from the consultant in the view of consultants and contractors are shown in Table 6. It can be concluded from Table 6 that the severest cause from the consultant is the delay of inspection by the consultant. It also can be concluded from Table 6 that the cause rankings in the view of consultants are almost similar with the view of contractors, the ranking span of causes according to the combined view ranges from $40.19 \%$ to $56.14 \%$ which means that all the causes from the consultant have a medium effect on delay of subway tunnel construction projects.

(5) Causes from Labor. The severity index and ranking of the 5 delay causes from labor in the view of consultants and contractors are shown in Table 7. It can be concluded from Table 7 that the severest cause from labor is the low productivity of laborers. It also can be concluded from Table 7 that the cause rankings in the view of consultants and the view of contractors are almost similar. There is a span in causes ranking in the combined view of consultants and contractors which ranges from $47.15 \%$ to $69.43 \%$ which means that the severities of the causes from labor are in the levels between medium and high.

(6) Causes from Environment. The severity index and ranking of the 5 delay causes from the environment in the view of consultants and contractors are shown in Table 8. It can be concluded from Table 8 that the severest cause from the environment is complicated geological conditions. It also can be concluded from Table 8 that the cause rankings in the view of consultants and the view of contractors are almost similar. There is a big span in causes ranking in the combined view of consultants and contractors which ranges from $38.62 \%$ to $74.00 \%$ which means that the severities of the causes from the environment are in the levels between low and high.

(7) Causes from Equipment and Material. The severity index and ranking of the 7 delay causes from equipment and material in the view of consultants and contractors are shown in Table 9. It can be concluded from Table 9 that the severest cause from equipment and material is the shortage of advanced large equipment. It also can be concluded from 
TABLE 3: Ranking of the causes from the owner.

\begin{tabular}{|c|c|c|c|c|c|c|}
\hline \multirow[t]{2}{*}{ Cause } & \multicolumn{2}{|c|}{$\begin{array}{c}\text { View of } \\
\text { consultants }\end{array}$} & \multicolumn{2}{|c|}{$\begin{array}{c}\text { View of } \\
\text { contractors }\end{array}$} & \multicolumn{2}{|r|}{$\begin{array}{l}\text { Combined } \\
\text { view }\end{array}$} \\
\hline & Rank & Severity index & Rank & Severity index & Rank & Severity index \\
\hline Progressing payments delay by the owner & 1 & 71.72 & 1 & 72.65 & 1 & 72.19 \\
\hline Postponement of the project by the owner & 2 & 68.21 & 3 & 68.38 & 2 & 68.30 \\
\hline Delay in providing construction materials & 3 & 66.47 & 2 & 69.36 & 3 & 67.92 \\
\hline Delays in decision making by the owner & 5 & 64.56 & 4 & 63.76 & 4 & 64.16 \\
\hline Change orders by the owner during construction period & 6 & 62.25 & 5 & 60.82 & 5 & 61.54 \\
\hline Late land handover to the contractor by the owner & 4 & 66.25 & 7 & 55.53 & 6 & 60.89 \\
\hline Poor financial status of the owner & 7 & 61.12 & 6 & 58.67 & 7 & 59.90 \\
\hline $\begin{array}{l}\text { Poor communication between the owner and other construction } \\
\text { parties }\end{array}$ & 8 & 57.95 & 9 & 48.90 & 8 & 53.43 \\
\hline Undefined scope of working & 9 & 54.62 & 8 & 51.03 & 9 & 52.83 \\
\hline Late issuing the approval documents by the owner & 10 & 52.38 & 10 & 47.83 & 10 & 50.11 \\
\hline
\end{tabular}

TABle 4: Ranking of the causes from designer.

\begin{tabular}{lcccccc}
\hline \multirow{2}{*}{ Cause } & \multicolumn{2}{c}{ View of consultants } & \multicolumn{2}{c}{ View of contractors } & \multicolumn{2}{c}{ Combined view } \\
& Rank & Severity index & Rank & Severity index & Rank & Severity index \\
\hline Late design works & 1 & 52.51 & 1 & 58.26 & 1 & 55.39 \\
Mistake in design & 2 & 46.58 & 2 & 49.35 & 2 & 47.97 \\
Inappropriate design & 3 & 40.69 & 3 & 43.17 & 3 & 41.93 \\
\hline
\end{tabular}

TABLE 5: Ranking of the causes from the contractor.

\begin{tabular}{|c|c|c|c|c|c|c|}
\hline \multirow{2}{*}{ Cause } & \multicolumn{2}{|c|}{ View of consultants } & \multicolumn{2}{|c|}{ View of contractors } & \multicolumn{2}{|c|}{ Combined view } \\
\hline & Rank & Severity index & Rank & Severity index & Rank & Severity index \\
\hline Ineffective scheduling of the project by the contractor & 1 & 65.60 & 2 & 62.30 & 1 & 63.95 \\
\hline Conflict between the contractor and other parties & 2 & 61.28 & 1 & 62.82 & 2 & 62.05 \\
\hline Difficulties in financing the project by the contractor & 3 & 61.01 & 3 & 61.95 & 3 & 61.48 \\
\hline $\begin{array}{l}\text { Poor communication by the contractor with other construction } \\
\text { parties }\end{array}$ & 5 & 47.18 & 4 & 59.22 & 4 & 53.20 \\
\hline Rework because of errors during construction & 4 & 48.71 & 5 & 50.75 & 5 & 49.73 \\
\hline Improper construction method & 6 & 46.38 & 7 & 47.36 & 6 & 46.87 \\
\hline Poor site supervision by the contractor & 8 & 41.18 & 6 & 48.02 & 7 & 44.60 \\
\hline Poor resource management & 7 & 42.40 & 8 & 45.24 & 8 & 43.82 \\
\hline
\end{tabular}

TABLE 6: Ranking of the causes from the consultant.

\begin{tabular}{lcccccc}
\hline \multirow{2}{*}{ Cause } & \multicolumn{2}{c}{ View of consultants } & \multicolumn{2}{c}{ View of contractors } & \multicolumn{2}{c}{ Combined view } \\
& Rank & Severity index & Rank & Severity index & Rank & Severity index \\
\hline Delay of inspection by the consultant & 1 & 57.58 & 2 & 54.69 & 1 & 56.14 \\
Inflexibility of the consultant & 2 & 53.86 & 1 & 56.82 & 2 & 55.34 \\
$\begin{array}{l}\text { Poor communication between the consultant and } \\
\text { other construction parties }\end{array}$ & 3 & 49.25 & 4 & 41.57 & 3 & 45.41 \\
Incapable and insufficient inspectors & 4 & 36.85 & 3 & 43.52 & 4 & 40.19 \\
\hline
\end{tabular}

TABLE 7: Ranking of the causes from labor.

\begin{tabular}{|c|c|c|c|c|c|c|}
\hline \multirow{2}{*}{ Cause } & \multicolumn{2}{|c|}{ View of consultants } & \multicolumn{2}{|c|}{ View of contractors } & \multicolumn{2}{|c|}{ Combined view } \\
\hline & Rank & Severity index & Rank & Severity index & Rank & Severity index \\
\hline Low productivity of laborers & 1 & 68.25 & 1 & 70.60 & 1 & 69.43 \\
\hline Insufficient laborers & 3 & 61.87 & 2 & 65.42 & 2 & 63.65 \\
\hline Low skill level of equipment-operator & 2 & 63.18 & 3 & 61.75 & 3 & 62.47 \\
\hline Personal conflicts among laborers & 4 & 50.37 & 5 & 46.52 & 4 & 48.45 \\
\hline Conflict between laborers and management team & 5 & 46.91 & 4 & 47.39 & 5 & 47.15 \\
\hline
\end{tabular}


TABLE 8: Ranking of the causes from environment.

\begin{tabular}{lcccccc}
\hline \multirow{2}{*}{ Cause } & \multicolumn{2}{c}{ View of consultants } & \multicolumn{2}{c}{ View of contractors } & \multicolumn{2}{c}{ Combined view } \\
& Rank & Severity index & Rank & Severity index & Rank & Severity index \\
\hline Complicated geological conditions & 1 & 74.38 & 1 & 73.62 & 2 & 74.00 \\
Poor terrain condition and wall rock quality & 2 & 67.55 & 3 & 66.27 & 1 & 66.91 \\
Weather condition & 3 & 46.14 & 2 & 55.70 & 3 & 50.92 \\
Poor effect on the drainage system & 4 & 41.86 & 4 & 39.71 & 4 & 40.79 \\
Natural disaster & 5 & 38.15 & 5 & 39.09 & 5 \\
\hline
\end{tabular}

Table 9 that the cause rankings in the view of consultants are almost similar with the view of contractors, but there are significant differences in the ranking of some causes, e.g., "shortage of advanced large equipment" respectively rank 3 and 1 in the view of consultants and contractors, "shortage in construction material" respectively rank 1 and 2, "serious damage to the equipment" respectively rank 6 and 4, and "material loss in the process of transportation" respectively rank 5 and 7. There is a span in causes ranking in the combined view of consultants and contractors which ranges from $57.73 \%$ to $70.30 \%$ which means that all the causes from equipment and material are in the levels between the medium and high effect on delay of subway tunnel construction projects.

(8) Causes from External Factors. The severity index and ranking of each delay cause from external factors in the view of consultants and contractors are shown in Table 10. It can be concluded from Table 10 that the severest cause from external factors is the national policy for subway tunnel construction, the second severest cause is award the project to lowest bid price, the severity index of both causes are bigger than $70 \%$. It also can be concluded from Table 10 that the cause rankings in the view of consultants are almost similar with the view of contractors, but there is a span in causes ranking according to the combined view of consultants and contractors which ranges from $45.22 \%$ to $75.17 \%$ which means that each cause from external factors has a medium or high effect on delay of subway tunnel construction projects.

6.2.2. Overall Causes Ranking. According to the view of consultants, the six most severe causes in subway tunnel construction projects in China are listed in Table 11. It is shown in Table 11 that among the top six delay causes, the first is related to the classification of environment, the second and the fourth are related to the classification of external factors, the third is related to the classification of the owner, and the fifth and sixth are related to the classification of equipment and material.

According to the view of contractors, the six most severe causes in subway tunnel construction projects in China are listed in Table 12. It is shown in Table 12 that among the top six delay causes, the first and the fourth are related to the classification of external factors, the second is related to the classification of environment, the third is related to the classification of the owner, the fifth is related to the classification of equipment, and the sixth is related to the classification of labor. It is also shown that the severity indexes of the top six delay causes are all higher than $70 \%$, the biggest severity index is $76.52 \%$.

According to the combined view of consultants and contractors, the six most severe causes in subway tunnel construction projects in China are listed in Table 13. It is shown in Table 13 that among all the delay causes, the top three causes are respectively related to the classification of external factor, environment, and the owner, the top affecting cause is the national policy for subway tunnel construction and its severity index is $75.17 \%$.

The severity indexes, rankings, and related classifications of all the investigated delay causes in subway tunnel construction projects in China are calculated and shown in Tables 11-13. It can be concluded from Tables 11-13 that the severity indexes of five causes are all above $70 \%$ according to the view of consultants, contractors, and their combined view, the five causes are national policy for subway tunnel construction, complicated geological conditions, payment delays by owners, award projects to lowest bid price, and shortage of advanced large equipment. It can be concluded that the severity indexes of two causes are less than $40 \%$ according to the view of consultants; the two causes are natural disaster and incapable and insufficient inspectors, the severity indexes of two causes are less than $40 \%$ according to the view of contractors; the two causes are the natural disaster and poor effect on the drainage system, the severity index of only one cause is than $40 \%$ according to the combined view; the cause is the natural disaster. Rankings of the top four causes in the view of consultants are almost similar with the view of contractors, but there is a difference in the ranking of "national policy for subway tunnel construction" which respectively rank 1st and 2nd in the view of consultants and contractors. Rankings of the top six causes according to the contractors' view are the same with the combined view.

6.2.3. Agreement and Disagreement of Severity Index. The top six delay causes in the agreement between consultants and contractors are listed in Table 14, the difference in the severity index values of those delay causes are lowest, the absolute difference in severity index value are all less than $0.95 \%$.

The top six delay causes in disagreement between consultants and contractors are listed in Table 15, the difference in the severity index values of those delay causes are highest than others, the absolute difference in severity index 
TABLE 9: Ranking of the causes from equipment and material.

\begin{tabular}{|c|c|c|c|c|c|c|}
\hline \multirow{2}{*}{ Cause } & \multicolumn{2}{|c|}{ View of consultants } & \multicolumn{2}{|c|}{ View of contractors } & \multicolumn{2}{|c|}{ Combined view } \\
\hline & Rank & Severity index & Rank & Severity index & Rank & Severity index \\
\hline Shortage of advanced large equipment & 3 & 69.52 & 1 & 71.08 & 1 & 70.30 \\
\hline Shortage in construction material & 1 & 71.05 & 2 & 65.71 & 2 & 68.38 \\
\hline Lack of equipment efficiency & 2 & 69.85 & 3 & 64.49 & 3 & 67.17 \\
\hline Changes in material types and specifications during construction & 4 & 63.26 & 5 & 61.90 & 4 & 62.58 \\
\hline Serious damage to the equipment & 6 & 59.85 & 4 & 62.31 & 5 & 61.08 \\
\hline Increasing prices of raw materials & 7 & 56.30 & 6 & 59.47 & 6 & 57.89 \\
\hline Material loss in the process of transportation & 5 & 60.17 & 7 & 55.28 & 7 & 57.73 \\
\hline
\end{tabular}

TABLE 10: Ranking of the causes from external factors.

\begin{tabular}{|c|c|c|c|c|c|c|}
\hline \multirow{2}{*}{ Cause } & \multicolumn{2}{|c|}{ View of consultants } & \multicolumn{2}{|c|}{ View of contractors } & \multicolumn{2}{|c|}{ Combined view } \\
\hline & Rank & Severity index & Rank & Severity index & Rank & Severity index \\
\hline National policy for subway tunnel construction & 1 & 73.81 & 1 & 76.52 & 1 & 75.17 \\
\hline Award the project to lowest bid price & 2 & 71.16 & 2 & 72.05 & 2 & 71.61 \\
\hline Limited construction area & 4 & 62.93 & 3 & 67.34 & 3 & 65.14 \\
\hline Lag in technology & 3 & 65.50 & 4 & 63.21 & 4 & 64.36 \\
\hline Changing of bankers' policy for loans & 5 & 52.72 & 6 & 50.37 & 5 & 51.55 \\
\hline Inconvenient site access & 6 & 47.06 & 5 & 52.30 & 6 & 49.68 \\
\hline Disturbance to public activities & 7 & 44.25 & 7 & 46.19 & 7 & 45.22 \\
\hline
\end{tabular}

value range from 6.84 to $12.04 \%$, there is no huge difference in the severity index values of all the causes between the consultants and contractors.

Table 16 lists the severity index difference of six most severe causes between the views of consultants and contractors. It shows the biggest difference value in the severity index of the six most severe causes ranges from $0.76 \%$ to $2.71 \%$, the calculated indexes according to the consultants' view are close to the contractors' view.

6.2.4. Classifications Ranking. All the delay causes can be divided into nine classifications. According to the view of consultants, contractors, and their combined view, the ranking of those classifications which are associated with the degree of severity are all listed in Table 17.

Table 17 illustrates that

(1) The three most severe classifications of delay in subway tunnel construction projects from the view of consultants are external factor, material, and the owner, while the three most severe classifications of a delay from the view of contractors are equipment, external factor, and material, while most severe classifications of a delay from the combined view are equipment, material, and the owner

(2) The least severe classification of delay in subway tunnel construction projects from the consultants' view and combined view are respectively designers and consultants, the least severe classification of a delay from the contractors' view is the same with the consultants' view
(3) There is a short span between the classifications' severity index and the span ranges from 46.59 to 66.41

6.2.5. Correlation of Severity Rank. Formula (3) is adopted to contrast the agreement between consultants and contractors on the severity of the delay causes in subway tunnel projects. According to the overall ranking of all the delay causes in Tables 11-13, the calculated rank correlation coefficient equals $76.3 \%$. It can be concluded from the rank correlation coefficient that the agreement between consultants and contractors is relatively good, so the results of this research are considered to be reliable.

\section{Discussion of Results}

\subsection{Top Six Delay Causes}

7.1.1. National Policy for Subway Tunnel Construction. The national policy for subway tunnel construction in China is described as changeable because of the contradictory developing strategy between the rural infrastructure and urban infrastructure, the policy leads to government investment increasing or decreasing. This delay cause has not been discussed in any studied literature.

7.1.2. Complicated Geological Conditions. Tunneling in the rock layers with complicated geological conditions is very difficult since the surrounding rock of the tunnel will become very loose and incapable of self-consolidating. The time of surrounding rock consolidation is difficult to predict and more variable than other construction procedures. 
TABLE 11: Ranking of all the delay causes according to view of consultants.

\begin{tabular}{|c|c|c|c|}
\hline Cause & Rank & Severity index & Related classifications \\
\hline Complicated geological conditions & 1 & 74.38 & Environment \\
\hline National policy for subway tunnel construction & 2 & 73.81 & External \\
\hline Progressing payments delay by the owner & 3 & 71.72 & Owner \\
\hline Award the project to lowest bid price & 4 & 71.16 & External \\
\hline Shortage in construction material & 5 & 71.05 & Material \\
\hline Lack of equipment efficiency & 6 & 69.85 & Equipment \\
\hline Shortage of advanced large equipment & 7 & 69.52 & Equipment \\
\hline Low productivity of laborers & 8 & 68.25 & Labor \\
\hline Postponement of the project by the owner & 9 & 68.21 & Owner \\
\hline Poor terrain condition and wall rock quality & 10 & 67.55 & Environment \\
\hline Delay in providing construction materials & 11 & 66.47 & Owner \\
\hline Late land handover to the contractor by the owner & 12 & 66.25 & Owner \\
\hline Ineffective scheduling of the project by the contractor & 13 & 65.6 & Contractor \\
\hline Lag in technology & 14 & 65.5 & External \\
\hline Delays in decision making by the owner & 15 & 64.56 & Owner \\
\hline Changes in material types and specifications during construction & 16 & 63.26 & Material \\
\hline Low skill level of equipment-operator & 17 & 63.18 & Labor \\
\hline Limited construction area & 18 & 62.93 & External \\
\hline Change orders by the owner during construction period & 19 & 62.25 & Owner \\
\hline Insufficient laborers & 20 & 61.87 & Labor \\
\hline Conflict between the contractor and other parties & 21 & 61.28 & Contractor \\
\hline Poor financial status of the owner & 22 & 61.12 & Owner \\
\hline Difficulties in financing the project by the contractor & 23 & 61.01 & Contractor \\
\hline Material loss in the process of transportation & 24 & 60.17 & Material \\
\hline Serious damage to the equipment & 25 & 59.85 & Equipment \\
\hline Poor communication between the owner and other construction parties & 26 & 57.95 & Owner \\
\hline Delay of inspection by the consultant & 27 & 57.58 & Consultant \\
\hline Increasing prices of raw materials & 28 & 56.3 & Material \\
\hline Undefined scope of working & 29 & 54.62 & Owner \\
\hline Inflexibility of the consultant & 30 & 53.86 & Consultant \\
\hline Changing of bankers' policy for loans & 31 & 52.72 & External \\
\hline Late design works & 32 & 52.51 & Designer \\
\hline Late issuing the approval documents by the owner & 33 & 52.38 & Owner \\
\hline Personal conflicts among laborers & 34 & 50.37 & Labor \\
\hline Poor communication between the consultant and other construction parties & 35 & 49.25 & Consultant \\
\hline Rework because of errors during construction & 36 & 48.71 & Contractor \\
\hline Poor communication by the contractor with other construction parties & 37 & 47.18 & Contractor \\
\hline Inconvenient site access & 38 & 47.06 & External \\
\hline Conflict between laborers and management team & 39 & 46.91 & Labor \\
\hline Mistake in design & 40 & 46.58 & Designer \\
\hline Improper construction method & 41 & 46.38 & Contractor \\
\hline Weather condition & 42 & 46.14 & Environment \\
\hline Disturbance to public activities & 43 & 44.25 & External \\
\hline Poor resource management & 44 & 42.4 & Contractor \\
\hline Poor effect on the drainage system & 45 & 41.86 & Environment \\
\hline Poor site supervision by the contractor & 46 & 41.18 & Contractor \\
\hline Inappropriate design & 47 & 40.69 & Designer \\
\hline Natural disaster & 48 & 38.15 & Environment \\
\hline Incapable and insufficient inspectors & 49 & 36.85 & Consultant \\
\hline
\end{tabular}

7.1.3. Payment Delays by Owners. Because of the high daily expenses involved in the tunneling works, it is very difficult for the contractors to fulfill the high costs without timely progress payment. The tunneling works always delay due to the shortage of cash flow, so payment delays by owners is a critical delay cause in the tunnel construction project especially for those projects with limited construction time.
7.1.4. Award Projects to Lowest Bid Price. A large number of owners prefer to award their projects to the contractors with lowest bid price, but those contractors always lack capabilities and experience in finishing a qualified project, which may cause a delay in the project completion. Hence, the awarding policy and the postqualification standards must be improved to reduce this problem. 
TABLE 12: Ranking of All the Delay Causes according to view of contractors.

\begin{tabular}{|c|c|c|c|}
\hline Cause & Rank & Severity index & Related classifications \\
\hline National policy for subway tunnel construction & 1 & 76.52 & External \\
\hline Complicated geological conditions & 2 & 73.62 & Environment \\
\hline Progressing payments delay by the owner & 3 & 72.65 & Owner \\
\hline Award the project to lowest bid price & 4 & 72.05 & External \\
\hline Shortage of advanced large equipment & 5 & 71.08 & Equipment \\
\hline Low productivity of laborers & 6 & 70.6 & Labor \\
\hline Delay in providing construction materials & 7 & 69.36 & Owner \\
\hline Postponement of the project by the owner & 8 & 68.38 & Owner \\
\hline Limited construction area & 9 & 67.34 & External \\
\hline Poor terrain condition and wall rock quality & 10 & 66.27 & Environment \\
\hline Shortage in construction material & 11 & 65.71 & Material \\
\hline Insufficient laborers & 12 & 65.42 & Labor \\
\hline Lack of equipment efficiency & 13 & 64.49 & Equipment \\
\hline Delays in decision making by the owner & 14 & 63.76 & Owner \\
\hline Lag in technology & 15 & 63.21 & External \\
\hline Conflict between the contractor and other parties & 16 & 62.82 & Contractor \\
\hline Serious damage to the equipment & 17 & 62.31 & Equipment \\
\hline Ineffective scheduling of the project by the contractor & 18 & 62.3 & Contractor \\
\hline Difficulties in financing the project by the contractor & 19 & 61.95 & Contractor \\
\hline Changes in material types and specifications during construction & 20 & 61.9 & Material \\
\hline Low skill level of equipment-operator & 21 & 61.75 & Labor \\
\hline Change orders by the owner during construction period & 22 & 60.82 & owner \\
\hline Increasing prices of raw materials & 23 & 59.47 & Material \\
\hline Poor communication by the contractor with other construction parties & 24 & 59.22 & Contractor \\
\hline Poor financial status of the owner & 25 & 58.67 & Owner \\
\hline Late design works & 26 & 58.26 & Designer \\
\hline Inflexibility of the consultant & 27 & 56.82 & Consultant \\
\hline Weather condition & 28 & 55.7 & Environment \\
\hline Late land handover to the contractor by the owner & 29 & 55.53 & Owner \\
\hline Material loss in the process of transportation & 30 & 55.28 & Material \\
\hline Delay of inspection by the consultant & 31 & 54.69 & Consultant \\
\hline Inconvenient site access & 32 & 52.3 & External \\
\hline Undefined scope of working & 33 & 51.03 & Owner \\
\hline Rework because of errors during construction & 34 & 50.75 & Contractor \\
\hline Changing of bankers' policy for loans & 35 & 50.37 & External \\
\hline Mistake in design & 36 & 49.35 & Designer \\
\hline Poor communication between the owner and other construction parties & 37 & 48.9 & Owner \\
\hline Poor site supervision by the contractor & 38 & 48.02 & Contractor \\
\hline Late issuing the approval documents by the owner & 39 & 47.83 & Owner \\
\hline Conflict between laborers and management team & 40 & 47.39 & Labor \\
\hline Improper construction method & 41 & 47.36 & Contractor \\
\hline Personal conflicts among laborers & 42 & 46.52 & Labor \\
\hline Disturbance to public activities & 43 & 46.19 & External \\
\hline Poor resource management & 44 & 45.24 & Contractor \\
\hline Incapable and insufficient inspectors & 45 & 43.52 & Consultant \\
\hline Inappropriate design & 46 & 43.17 & Designer \\
\hline Poor communication between the consultant and other construction parties & 47 & 41.57 & Consultant \\
\hline Poor effect on the drainage system & 48 & 39.71 & Environment \\
\hline Natural disaster & 49 & 39.09 & Environment \\
\hline
\end{tabular}

7.1.5. Shortage of Advanced Large Equipment. Many tunnel contractors in China are small companies and do not own enough advanced large equipment that is required in subway tunneling. Nowadays, there are more and more subway tunnel projects in China, the shortage of advanced large equipment may extend the tunneling time and cause project delay.

7.1.6. Low Productivity of Laborers. Nowadays, most of the construction workers are peasant laborers in China. Those peasant laborers lack theoretical basis knowledge and tunnel construction experience, they are not familiar with all kinds of code standards and trends of technological development, which may cause a delay in the project completion. Hence, the continuing education and skills training must be used to improve the productivity of laborers.

7.2. Advice to Reduce Overtime in Tunnel Construction. The advice to reduce and control the delay in subway tunnel construction projects are as follows: 
TABLE 13: Ranking of all the delay causes according to the combined view.

\begin{tabular}{|c|c|c|c|}
\hline Cause & Rank & Severity index & Related classifications \\
\hline National policy for subway tunnel construction & 1 & 75.17 & External \\
\hline Complicated geological conditions & 2 & 74 & Environment \\
\hline Progressing payments delay by the owner & 3 & 72.19 & Owner \\
\hline Award the project to lowest bid price & 4 & 71.61 & External \\
\hline Shortage of advanced large equipment & 5 & 70.3 & Equipment \\
\hline Low productivity of laborers & 6 & 69.43 & Labor \\
\hline Shortage in construction material & 7 & 68.38 & Material \\
\hline Postponement of the project by the owner & 8 & 68.3 & Owner \\
\hline Delay in providing construction materials & 9 & 67.92 & Owner \\
\hline Lack of equipment efficiency & 10 & 67.17 & Equipment \\
\hline Poor terrain condition and wall rock quality & 11 & 66.91 & Environment \\
\hline Limited construction area & 12 & 65.14 & External \\
\hline Lag in technology & 13 & 64.36 & External \\
\hline Delays in decision making by the owner & 14 & 64.16 & Owner \\
\hline Ineffective scheduling of the project by the contractor & 15 & 63.95 & Contractor \\
\hline Insufficient laborers & 16 & 63.65 & Labor \\
\hline Changes in material types and specifications during construction & 17 & 62.58 & Material \\
\hline Low skill level of equipment operator & 18 & 62.47 & Labor \\
\hline Conflict between the contractor and other parties & 19 & 62.05 & Contractor \\
\hline Change orders by the owner during construction period & 20 & 61.54 & owner \\
\hline Difficulties in financing the project by the contractor & 21 & 61.48 & Contractor \\
\hline Serious damage to the equipment & 22 & 61.08 & Equipment \\
\hline Late land handover to the contractor by the owner & 23 & 60.89 & Owner \\
\hline Poor financial status of the owner & 24 & 59.9 & Owner \\
\hline Increasing prices of raw materials & 25 & 57.89 & Material \\
\hline Material loss in the process of transportation & 26 & 57.73 & Material \\
\hline Delay of inspection by the consultant & 27 & 56.14 & Consultant \\
\hline Late design works & 28 & 55.39 & Designer \\
\hline Inflexibility of the consultant & 29 & 55.34 & Consultant \\
\hline Poor communication between the owner and other construction parties & 30 & 53.43 & Owner \\
\hline Poor communication by the contractor with other construction parties & 31 & 53.2 & Contractor \\
\hline Undefined scope of working & 32 & 52.83 & Owner \\
\hline Changing of bankers' policy for loans & 33 & 51.55 & External \\
\hline Weather condition & 34 & 50.92 & Environment \\
\hline Late issuing the approval documents by the owner & 35 & 50.11 & owner \\
\hline Rework because of errors during construction & 36 & 49.73 & Contractor \\
\hline Inconvenient site access & 37 & 49.68 & External \\
\hline Personal conflicts among laborers & 38 & 48.45 & Labor \\
\hline Mistake in design & 39 & 47.97 & Designer \\
\hline Conflict between laborers and management team & 40 & 47.15 & Labor \\
\hline Improper construction method & 41 & 46.87 & Contractor \\
\hline Poor communication between the consultant and other construction parties & 42 & 45.41 & Consultant \\
\hline Disturbance to public activities & 43 & 45.22 & External \\
\hline Poor site supervision by the contractor & 44 & 44.6 & Contractor \\
\hline Poor resource management & 45 & 43.82 & Contractor \\
\hline Inappropriate design & 46 & 41.93 & Designer \\
\hline Poor effect on the drainage system & 47 & 40.79 & Environment \\
\hline Incapable and insufficient inspectors & 48 & 40.19 & Consultant \\
\hline Natural disaster & 49 & 38.62 & Environment \\
\hline
\end{tabular}

(1) The government officers should give the necessary attention to the following advice:

(a) To improve the management strategies of construction parties and the skills of laborers, the ministry of construction should conduct some annual training programs in cooperation with the Chinese contractors association. (b) The local government should take some risk for contractors when owners delay the payments to the contractors because a large number of contracting companies in China are small and lack capital.

(c) The local government should modify and improve the construction laws and rules on time to 
TABLE 14: Top six causes in agreement between consultants and contractors.

\begin{tabular}{lcccc}
\hline Cause & Overall rank & \multicolumn{2}{c}{$\begin{array}{c}\text { Severity index } \\
\text { Consultants' view }\end{array}$} & $\begin{array}{c}\text { Absolute difference in } \\
\text { Ceverity index }\end{array}$ \\
\hline Postponement of the project by the owner & 8 & 68.21 & 68.38 & 0.17 \\
Conflict between laborers and management team & 40 & 46.91 & 47.39 & 0.48 \\
Complicated geological conditions & 2 & 74.38 & 73.62 & 0.76 \\
Delays in decision making by the owner & 14 & 64.56 & 63.76 & 0.80 \\
Award the project to lowest bid price & 4 & 71.16 & 72.05 & 0.89 \\
Progressing payments delay by the owner & 3 & 71.72 & 72.65 & 0.93 \\
\hline
\end{tabular}

TABLE 15: Top six causes in disagreement between consultants and contractors.

\begin{tabular}{|c|c|c|c|c|}
\hline \multirow{2}{*}{ Cause } & \multirow{2}{*}{ Overall rank } & \multicolumn{2}{|c|}{ Severity index } & \multirow{2}{*}{$\begin{array}{c}\text { Absolute } \\
\text { difference } \\
\text { in severity index }\end{array}$} \\
\hline & & Consultants' view & Contractors' view & \\
\hline Poor site supervision by the contractor & 44 & 41.18 & 48.02 & 6.84 \\
\hline $\begin{array}{l}\text { Poor communication between the consultant and other } \\
\text { construction parties }\end{array}$ & 42 & 49.25 & 41.57 & 7.68 \\
\hline $\begin{array}{l}\text { Poor communication between the owner and other construction } \\
\text { parties }\end{array}$ & 30 & 57.95 & 48.9 & 9.05 \\
\hline Weather condition & 34 & 46.14 & 55.7 & 9.56 \\
\hline Late land handover to the contractor by the owner & 23 & 66.25 & 55.53 & 10.72 \\
\hline $\begin{array}{l}\text { Poor communication by the contractor with other construction } \\
\text { parties }\end{array}$ & 31 & 47.18 & 59.22 & 12.04 \\
\hline
\end{tabular}

TABLE 16: Severity index difference of the top six causes between consultants and contractors.

\begin{tabular}{|c|c|c|c|c|}
\hline \multirow{2}{*}{ Cause } & \multirow{2}{*}{ Overall rank } & \multicolumn{2}{|c|}{ Severity index } & \multirow{2}{*}{ Absolute difference in severity index } \\
\hline & & Consultants' view & Contractors' view & \\
\hline $\begin{array}{l}\text { National policy for subway tunnel } \\
\text { construction }\end{array}$ & 1 & 73.81 & 76.52 & 2.71 \\
\hline Complicated geological conditions & 2 & 74.38 & 73.62 & 0.76 \\
\hline Progressing payments delay by the owner & 3 & 71.72 & 72.65 & 0.93 \\
\hline Award the project to lowest bid price & 4 & 71.16 & 72.05 & 0.89 \\
\hline Shortage of advanced large equipment & 5 & 69.52 & 71.08 & 1.56 \\
\hline Low productivity of laborers & 6 & 68.25 & 70.6 & 2.35 \\
\hline
\end{tabular}

accommodate to the development plan of China. The modified rules should make it possible for contractors to earn more profit.

(2) Owners should carefully consider the following advice:

(a) Owners should give enough time for contractors to plan, design, and construct tunnel projects, this may be useful in avoiding or reducing time delay. (b) Owners should pay the progress payment to contractors on time, otherwise, the projects may delay because the contractors cannot afford to finance the construction work.

(c) Owners should check the capabilities, experiences, and resources of the suitable bidders before awarding the contracts to them.

(d) Owners should confirm the detailed site investigation before the construction phase and avoid the changing of site investigation. 
TABLE 17: Ranking of main classifications.

\begin{tabular}{|c|c|c|c|c|c|c|}
\hline \multirow{2}{*}{ Classification } & \multicolumn{2}{|r|}{ View of consultants } & \multicolumn{2}{|r|}{ View of contractors } & \multicolumn{2}{|r|}{ Combined view } \\
\hline & Rank & Classification severity index & Rank & Classification severity index & Rank & Classification severity index \\
\hline Owner & 3 & 62.55 & 4 & 59.69 & 3 & 61.12 \\
\hline Designer & 9 & 46.59 & 8 & 50.26 & 9 & 48.43 \\
\hline Contractor & 7 & 51.72 & 7 & 54.71 & 7 & 53.21 \\
\hline Consultant & 8 & 49.39 & 9 & 49.15 & 8 & 49.27 \\
\hline Labor & 5 & 58.12 & 5 & 58.34 & 5 & 58.23 \\
\hline Environment & 6 & 53.62 & 6 & 54.88 & 6 & 54.25 \\
\hline Material & 2 & 62.70 & 3 & 60.59 & 2 & 61.65 \\
\hline Equipment & 1 & 66.41 & 1 & 65.96 & 1 & 66.19 \\
\hline External factor & 4 & 59.63 & 2 & 61.14 & 4 & 60.39 \\
\hline
\end{tabular}

(e) To make the required decisions on time, owners should well communicate with other construction parties.

(3) Consultants should give necessary attention to the following advice:

(a) Consultants should offer enough information which is necessary for interpreting the construction drawings and laying out the works.

(b) Consultants should adopt more suitable ways to evaluate construction works and compromise between high quality and low expenditure.

(4) Contractors should carefully think about the following advice:

(a) To improve labor efficiency, contractors should assign a large percentage of trained and skilled laborers in construction projects, especially in large tunnel construction projects.

(b) To improve work efficiency, contractors should assign enough advanced equipment and use new materials in large tunnel construction projects $[24,25]$.

(c) To achieve the specified expenditure, time, and quality, contractors should well communicate with owners and consultants.

\section{Conclusion}

The delay causes of subway tunnel construction projects in China have been studied by a field survey, the field survey involved 87 consultants and 91 contractors. The 49 delay causes have been identified into 9 categories, the severity indexes and ranks of the delay causes have been discussed according to the view of consultants and contractors.

The responses of consultants and contractors about the delay rate in subway tunnel construction projects during the last 5 years show the following:

(1) $68.8 \%$ of the responding consultants pointed out that the average duration of their participated tunnel projects is $20 \%$ to $30 \%$ longer than the planned project duration.

(2) $85.7 \%$ of the responding contractors pointed out that the average duration of their participated tunnel projects is $20 \%$ to $40 \%$ longer than the planned project duration.

(3) Neither contractors nor consultants pointed out any delay rate of more than $100 \%$ of the planned project duration.

The conclusions from the statistical analysis of research data are shown as follows:

(1) Neither contractors nor consultants indicated any cause with no effect on the delay of subway tunnel construction projects.

(2) The severity index of each delay cause is more than $38 \%$. The severity index of each classification ranges from 46.59 to 66.41 .

According to the combined view of consultants and contractors, the six most severe delay causes are national policy for subway tunnel construction, complicated geological conditions, payment delays by owners, award projects to lowest bid price, shortage of advanced large equipment, and low productivity of laborers. Conversely, the six least severe delay causes are poor site supervision by the contractor, poor resource management, inappropriate design, poor effect on the drainage system, incapable and insufficient inspectors, and natural disaster.

It also can be concluded from the combined view of consultants and contractors that the three most severe classifications of delay in subway tunnel construction projects are equipment, material, and the owner.

The value of the rank correlation coefficient equals $76.3 \%$ which illustrates that the agreement on the severity ranking of delay causes is relatively reliable. These studied results reveal that all the investigated causes have relevance to the delay problems in subway tunnel construction projects in China.

\section{Data Availability}

The data used to support the findings of this study are included within the article.

\section{Conflicts of Interest}

The authors declare that there are no conflicts of interest regarding the publication of this paper. 


\section{Acknowledgments}

The authors gratefully acknowledge the financial support of Key Project of Research Center for Mining \& Metallurgy Culture and Economic \& Social Development in the Middle Reaches of the Yangtze River (2017kywh03), Natural Science Foundation of China (51908324), and Science and Technology Project of Hubei Province Construction Department (2017A16).

\section{References}

[1] A. Enshassi, K. Al-Hallaq, and S. Mohamed, "Causes of contractor's business failure in developing countries: the case of Palestine," Journal of Construction in Developing Countries, vol. 11, no. 2, pp. 1-14, 2006.

[2] R. Leibing, The Construction Industry: Processes, Players, and Practices, Prentice-Hall, Upper Saddle River, NJ, USA, 2001.

[3] S. Ahmed, S. Azhar, P. Kappagantula, and D. Gollapudi, "Delays in construction: a brief study of the Florida construction industry," in Proceedings of the 39th Annual Conference of the Associated Schools of Construction, Clemson University, Clemson, SC, USA, 2003.

[4] C. Kaliba, M. Muya, and K. Mumba, "Cost escalation and schedule delays in road construction projects in Zambia," International Journal of Project Management, vol. 27, no. 5, pp. 522-531, 2009.

[5] F. Nega, "Causes and effects of cost overrun on public building construction projects in Ethiopia," MS thesis, Addis Ababa Univ., Addis Ababa, Ethiopia, 2008.

[6] K. K. Chitkara, Construction Project Management, Planning, Scheduling, and Controlling, Tata McGraw-Hill, New Delhi, India, 4th edition, 2004.

[7] J. Al-Najjar, "Factors influencing time and cost overruns on construction projects in the Gaza strip," MS thesis, Islamic University of Gaza, Gaza, Palestine, 2008.

[8] A. S.-T. Chang, "Reasons for cost and schedule increase for engineering design projects," Journal of Management in Engineering, vol. 18, no. 1, pp. 29-36, 2002.

[9] K. P. Hoshino, R. B. Brown, J. J. Ciccarelli et al., Forensic Schedule Analysis, TCM Framework: 6.4-Forensic Performance Assessment, AACE International Recommended Practice No. 29R-03, AACE International, Inc, Morgantown, WV, USA, 2007.

[10] A. Kazemi, A. Katebi, and M. H. Kazemi, "Causes of delay in construction projects: the case of oil and gas projects," in Proceedings of the 2018 International Conference on Modern Trends in Science, Engineering and Technology, Dubai, UAE, 2018.

[11] B. Zarei, H. Sharifi, and Y. Chaghouee, "Delay causes analysis in complex construction projects: a semantic network analysis approach," Production Planning \& Control, vol. 29, no. 3, 2017.

[12] R. F. Aziz and A. A. Abdel-Hakam, "Exploring delay causes of road construction projects in Egypt," Alexandria Engineering Journal, vol. 55, no. 2, pp. 1515-1539, 2016.

[13] A. H. Al-Momani, "Construction delay: a quantitative analysis," International Journal of Project Management, vol. 18, no. 1, pp. 51-59, 2000

[14] A. M. Odeh and H. T. Battaineh, "Causes of construction delay: traditional contracts," International Journal of Project Management, vol. 20, no. 1, pp. 67-73, 2002.
[15] S. A. Assaf and S. Al-Hejiji, "Causes of delay in large construction projects," International Journal of Project Management, vol. 24, no. 4, pp. 349-357, 2006.

[16] J. Ahn and R. E. Minchin, "Identifying causes for delay in highway construction projects," in Proceedings of the 2007 Transportation Research Board 86th Annual Meeting, Washington, DC, USA, 2007.

[17] A. Enshassi and J. Abu Mosa, "Risk management in building projects: owners' perspective," Islamic University Journal, vol. 16, no. 1, pp. 95-123, 2008.

[18] J.-B. Yang, C.-C. Yang, and C.-K. Kao, "Evaluating schedule delay causes for private participating public construction works under the build-operate-transfer model," International Journal of Project Management, vol. 28, no. 6, pp. 569-579, 2010.

[19] I. Mahamid, A. Bruland, and N. Dmaidi, "Causes of delay in road construction projects," Journal of Management in Engineering, vol. 28, no. 3, pp. 300-310, 2012.

[20] D. S. Santoso and S. Soeng, "Analyzing delays of road construction projects in Cambodia: causes and effects," Journal of Management in Engineering, vol. 32, no. 6, Article ID 05016020, 2016.

[21] A. Y. Y. Alfakhri, A. Ismail, and A. Khoiry, “A conceptual model of delay factors affecting road construction projects in Libya," Journal of Engineering Science \& Technology, vol. 12, no. 12, pp. 3286-3298, 2017.

[22] G. Bilgin, I. Dikmen, and M. T. Birgonul, "An ontology-based approach for delay analysis in construction," KSCE Journal of Civil Engineering, vol. 22, pp. 384-398, 2017.

[23] T. Wang, G. Zhou, J. Wang, and X. Zhao, "Stochastic analysis for the uncertain temperature field of tunnel in cold regions," Tunnelling and Underground Space Technology, vol. 59, pp. 7-15, 2016.

[24] D. Zhang, Z. Zhang, T. Cheng, and X. Zhao, "Multi-factorial analysis on vault stability of an unsymmetrically loaded tunnel using response surface method," International Journal of Engineering, vol. 32, no. 11, pp. 1570-1576, 2019.

[25] T. Wang, G. Zhou, J. Wang, and L. Yin, "Stochastic analysis of uncertainty mechanical characteristics for surrounding rock and lining in cold region tunnels," Cold Regions Science and Technology, vol. 145, pp. 160-168, 2018. 